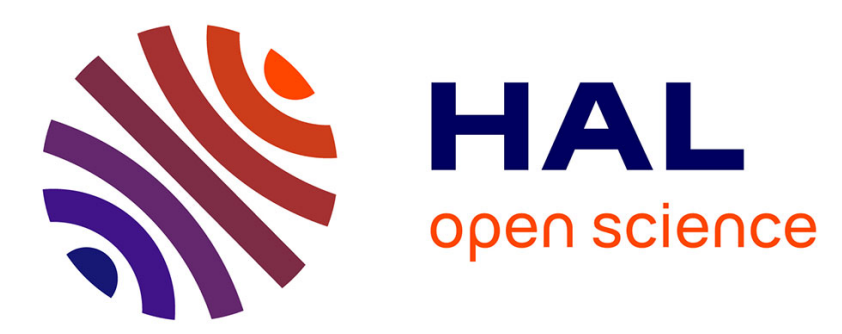

\title{
Contribution of Debye series to particle characterization with holography and the photonic jet method
}

Fabrice R. A. Onofri, Fabrice Lamadie, Matthias Sentis

\section{To cite this version:}

Fabrice R. A. Onofri, Fabrice Lamadie, Matthias Sentis. Contribution of Debye series to particle characterization with holography and the photonic jet method. Digital Holography and Three-Dimensional Imaging, 2019, Bordeaux, France. pp.Th1B.7, 10.1364/DH.2019.Th1B.7 . hal-02370277

\section{HAL Id: hal-02370277 \\ https://hal.science/hal-02370277}

Submitted on 19 Nov 2019

HAL is a multi-disciplinary open access archive for the deposit and dissemination of scientific research documents, whether they are published or not. The documents may come from teaching and research institutions in France or abroad, or from public or private research centers.
L'archive ouverte pluridisciplinaire HAL, est destinée au dépôt et à la diffusion de documents scientifiques de niveau recherche, publiés ou non, émanant des établissements d'enseignement et de recherche français ou étrangers, des laboratoires publics ou privés. 
F. R. A. Onofri, F. Lamadie, and M. P. L. Sentis, "Contribution of Debye series to particle characterization with holography and the photonic jet method," in Digital Holography and Three-Dimensional Imaging 2019, OSA Technical Digest (Optical Society of America, 2019), paper Th1B.7 https://doi.org/10.1364/DH.2019.Th1B.7

\title{
Contribution of Debye series to particle characterization with holography and the photonic jet method
}

\author{
Fabrice R.A. Onofri ${ }^{1 *}$, Fabrice Lamadie ${ }^{2}$, Matthias P.L. Sentis ${ }^{3}$ \\ 1 Aix-Marseille Université, CNRS, IUSTI, UMR 7343, 13453 Marseille Cedex 13, France \\ 2 CEA, DEN, DTEC, SGCS, F-30207 Bagnols-sur-Cèze, France \\ 3 Toulouse, France \\ Author e-mail address: fabrice.onofri@univ-amu.fr
}

\begin{abstract}
Physical insights are provided on the relative contributions of the scattering processes (pure diffraction, specular reflection, tunneling and grazing waves, single refraction...) in the reconstruction of the photonic jet of spherical particles with Digital-in-Line Holography.

OCIS codes: (090.1995) Digital holography, (050.1940) Diffraction, 290.5850 Scattering, particles, (280.2490) Flow diagnostics
\end{abstract}

\section{Introduction}

We have recently proposed a new and numerical-effective method to measure with Digital-in-Line Holography $(\mathrm{DIH})[1]$ the refractive index (real, m) of transparent and spherical particles [2-4]. This "photonic jet method" (PJM) is based on the analysis of the "photonic jet" (also named "forward caustic" [3,5]) produced by the aforementioned particles. In the Geometrical Optics Approximation (GOA) framework, this optical phenomenon is attributed to the single refracted rays that are scattered by the particle along the optical axis direction. By equating a transparent spherical particle to a small ball lens, it is straightforward to rely its focal length, $\mathrm{f}$, to its radius, a, and refractive index, $\mathrm{f}=\mathrm{ma} /(2(\mathrm{~m}-1))$ [6]. After measuring the size of the particle with classical methods used in DIH (back propagation or inverse methods), its refractive index can be directly deduced from the relative location of the photonic jet maxima according to the particle center. This method works well for refractive particles $(\mathrm{m}>1$, e.g. droplets and beads in gas or liquids) as well as reflective ones $(\mathrm{m}<1$, gas bubbles in liquid or some liquid droplets in liquids). As an illustration, it allows obtaining, at almost no additional computational cost, an accuracy of $\pm 3.710^{-3}$ on the refractive index of liquid-liquid particles with radius within the range [30-1250] $\mu \mathrm{m}$. This PJM method opens huge perspectives in domains requiring the characterization of the composition of objects (particles, cells...) in addition to their morphological (size and shape) and dynamical (velocity, acceleration) properties.

In the frame of the scalar diffraction theory, and more particularly the Fresnel's Approximation, we have recently demonstrated that the PJ reconstructed by DIH is formally similar to the Airy pattern of a thin lens $[4,6]$, and that the reconstructed near field exhibits some real $(\mathrm{m}>1)$ or virtual features $(\mathrm{m}<1)$. To further extend the capability and accuracy of the DIH-PJM, it is a priori necessary to not only account for Geometrical and Physical Optics (GPOA) effects but also semi-classical effects (e.g. [7-11]). We investigate in this communication the interest of Debye series for this purpose and as an alternative $[12,13]$.

\section{Direct holograms simulations and backpropagation}

Direct simulations of particle near-field and holograms are calculated with Debye's electromagnetic theory (e.g. [12]). The latter allows accounting rigorously for the relative contributions and/or interferences of a part or all partial waves contributing to the total scattering described by the Lorenz-Mie Theory (LMT). To reconstruct the near field, we use backpropagations based on Fresnel, Rayleigh-Sommerfield and the angular spectral methods. When the near field is reconstructed, the particle and photonic jet characteristics are retrieved using classical meritfunctions, i.e. the Tenengrad variance of the modulus of the reconstructed field and the variance of its imaginary part respectively. The reader is referred to [2-4] for more details on the mathematical, the numerical, the backpropagation and tracking schemes as well as experimental tests, in free $[3,4,14]$ or astigmatic media [2]. Note that the MATLAB ${ }^{\mathrm{TM}}$ code allowing the calculation of the near field and hologram with Debye series is available upon request from the authors.

\section{Results and discussion}

For DIH, which operates in the small-angle scattering region, it is usually believed that holograms result exclusively from the term $\mathrm{p}=0$ of Debye series. This is an implicit assumption when, for instance, the opaque disk model is used to model the wave front exiting the particle [6]. Indeed, this terms, noted herein $\mathrm{p}=0_{\text {all, }}$, accounts for various contributions: a pure diffraction (noted $\mathrm{p}=0_{\text {diff }}$ herein) term which does not depend on the particle material properties 


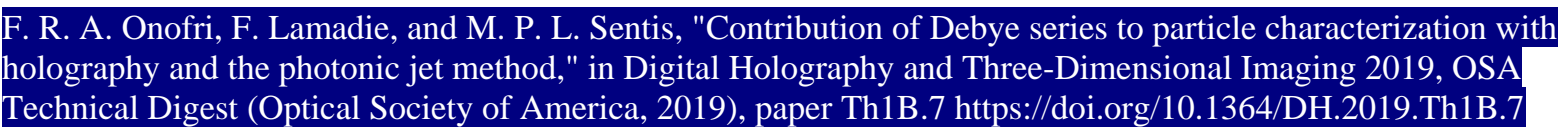

(i.e. refractive index) $[10,15])$, specular reflection below $\left(\mathrm{p}=0_{<}\right)$and above $(\mathrm{p}=0>)$ the grazing incidence region, tunneling and surface waves $\left(\mathrm{p}=0_{\text {tunsw }}\right)$. As already mentioned, except the term $\mathrm{p}=0_{\text {diff }}$, all other optical phenomena are commonly neglected in DIH literature - without any justification. By now, we have already proven indirectly that it is mandatory to account for the term $\mathrm{p}=1$ (single refraction) to reproduce the main features of the PJ [2-4]. The results obtained with the Debye theory show that this term is not sufficient to reproduce all the fine structure of the PJ, see Fig. 1. In order to achieve this, it is probably necessary to account for the interference of the terms $\mathrm{p}=0$ and $\mathrm{p}=1$ onto the DIH sensor, while the influence of higher refraction terms $(\mathrm{p}>1)$ is thought to be not so crucial. Fig. 1 illustrates also clearly the higher complexity of the near field compared to the (apparent) poverty of the diffraction patterns calculated for a distance of $\mathrm{z}=100 \mathrm{~mm}$ from a methanol droplet in air. All these aspects will be discussed and most notably the influence and importance of the different scattering processes onto the quality of the reconstructions and the estimation of the particle properties.
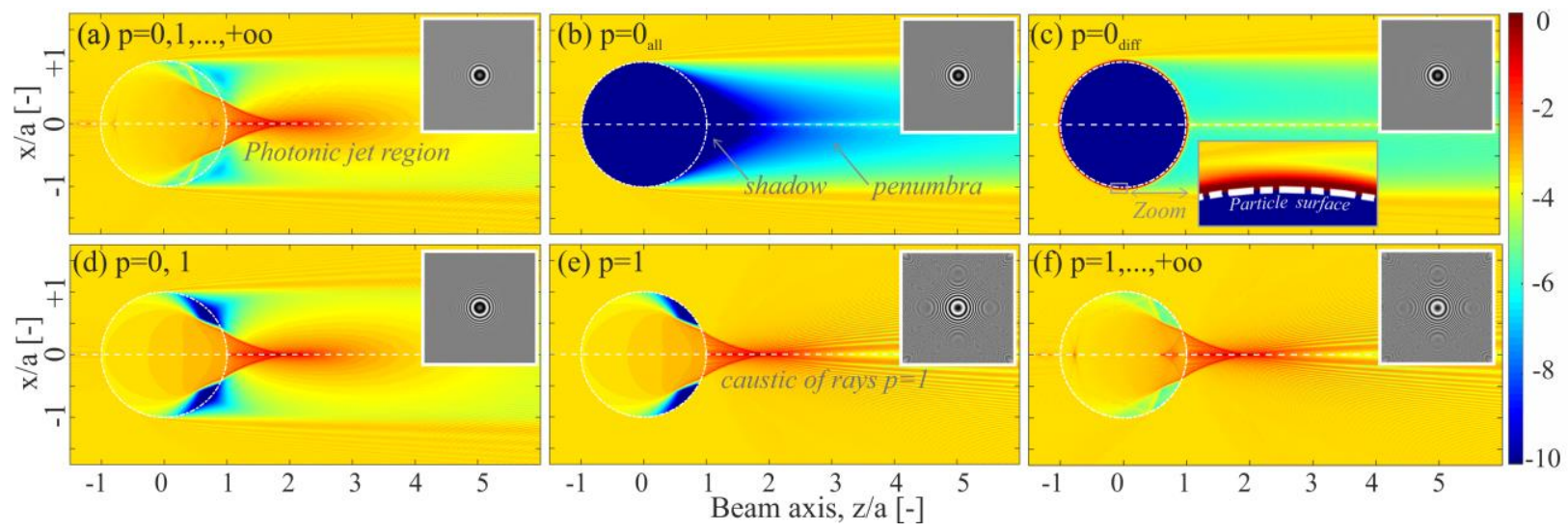

Fig. 1. Color maps of the logarithm of the normalized electromagnetic near-field intensity calculated with the Debye theory around a methanol droplet in air with size parameter $\alpha=2 \pi \mathrm{a} / \lambda=600, \mathrm{a} \approx 101.6 \mu \mathrm{m}$ and $\mathrm{m}=1.3145$ for the wavelength $\lambda=0.532 \mu \mathrm{m}$.

(a) All scattering processes; (b) diffraction, specular reflection, surface waves,...; (c) pure diffraction; (d) all $\mathrm{p}=0$ terms interfering with single refraction; (e) pure single refraction; (f) all refracted terms. The corresponding hologram $(\mathrm{z}=0.1 \mathrm{~m})$ is displayed in the top right corner for a quadratic sensor with resolution: 1024x1024 pixels of $8 \mu \mathrm{m}$.

\section{References}

1. $\quad$ B. J. Thompson, "Holographic particle sizing techniques," Journal of Physics E: Scientific Instruments 7, 781 (1974).

2. M. P. L. Sentis, L. Bruel, S. Charton, F. R. A. Onofri, and F. Lamadie, "Digital in-line holography for the characterization of flowing particles in astigmatic optical systems," Opt. Lasers Eng. 88, 184-196 (2017).

3. M. P. L. Sentis, F. R. A. Onofri, and F. Lamadie, "Photonic jet reconstruction for particle refractive index measurement by digital inline holography," Opt. Express 25, 867-873 (2017).

4. M. P. L. Sentis, F. R. A. Onofri, and F. Lamadie, "Bubbles, drops, and solid particles recognition from real or virtual photonic jets reconstructed by digital in-line holography," Opt. Lett. 43, 2945-2948 (2018).

5. L. Tian, H. Gao, and G. Barbastathis, "Digital holographic imaging of multi-phase flows," in Imaging and Applied Optics, OSA Technical Digest (CD) (Optical Society of America, 2011), CWB5.

6. J. W. Goodman, "Introduction to Fourier Optic," Mac. Graw-Hill, New York (1960).

7. M. P. L. Sentis, F. R. A. Onofri, L. Méès, and S. Radev, "Scattering of light by large bubbles: Coupling of geometrical and physical optics approximations," J. Quant. Spectrosc. Radiat. Transf. 170, 8-18 (2016).

8. F. R. A. Onofri, K. F. Ren, M. Sentis, Q. Gaubert, and C. Pelcé, "Experimental validation of the vectorial complex ray model on the inter-caustics scattering of oblate droplets," Opt. Express 23, 15768-15773 (2015).

9. F. R. A. Onofri, S. Radev, M. Sentis, and S. Barbosa, "Physical-optics approximation of near-critical-angle scattering by spheroidal bubbles," Opt. Lett. 37, 4780-4782 (2012).

10. H. M. Nussenzveig, Diffraction effects in semiclassical scattering (Cambridge University Press, Cambridge, 1992).

11. F. R. A. Onofri and M. P. L. Sentis, "Light Scattering by Large Bubbles," in Springer Series in Light Scattering: Volume 2: Light Scattering, Radiative Transfer and Remote Sensing, A. Kokhanovsky, ed. (Springer International Publishing, Cham, 2018), pp. 109149.

12. E. A. Hovenac and J. A. Lock, "Assessing the contribution of surface waves and complex rays to far-field scattering by use of the Debye series," J. Opt. Soc. Am. A 9, 781-795 (1992).

13. Y. Wu, X. Wu, L. Yao, M. Brunel, S. Coëtmellec, R. Li, D. Lebrun, H. Zhou, G. Gréhan, and K. Cen, "Characterizations of transparent particle holography in near-field using Debye series," Appl. Opt. 55, A60-A70 (2016).

14. F. Lamadie, L. Bruel, and M. Himbert, "Digital holographic measurement of liquid-liquid two-phase flows," Opt. Lasers Eng. 50, 1716-1725 (2012)

15. J. A. Lock and P. Laven, "Mie scattering in the time domain. Part II. The role of diffraction," J. Opt. Soc. Am. A 28, 1096-1106 (2011). 